\title{
Evaluation of Porosity in Gas-Atomized Powder by Synchrotron X-ray CT and Investigation of the Effect of Gas Species*1
}

\author{
Noriharu Yodoshi*2, Takahide Endo and Naoya Masahashi \\ Cooperative Research and Development Center for Advanced Materials, Institute for Materials Research, Tohoku University, \\ Sendai 980-8577, Japan
}

The presence of pores in gas-atomized alloy powders induces a significant deterioration in the properties of the final product. However, there is no established technique to quantitatively analyze the porosity of gas-atomized powders. In this study, the pores in gas-atomized amorphous $\mathrm{Fe}_{76} \mathrm{Si}_{9} \mathrm{~B}_{10} \mathrm{P}_{5}$ powder particles prepared under different atomization conditions were analyzed in detail using synchrotron radiation X-ray computed tomography. This technique allowed the detection of small pores with diameters below $10 \mu \mathrm{m}$. It also enabled the quantification of the porosity; thus, the pore diameter and volume ratio under different atomization conditions were determined. The volume ratio of the pores with the use of low-pressure $\mathrm{Ar}$ as the atomization gas was lower than that with the use of high-pressure Ar. The use of a low-pressure gas during spraying induced an increase in the diameter of the powder particles, thereby resulting in the presence of numerous irregular-shaped particles. The results of X-ray diffraction confirmed the partial precipitation of a crystalline phase with a decrease in the cooling rate. The use of 3 or $7 \%$ $\mathrm{Ar}-\mathrm{H}_{2}$ mixtures as the atomization gas induced a decrease in the number and volume of pores, without affecting the particle size and cooling rate. The presence of $\mathrm{H}_{2}$ as a reducing gas suppressed the surface oxidation of the droplet during the atomization of the molten-metal stream, which allowed trapped gas bubbles to be efficiently removed before solidification. This study demonstrated that the total pore volume in a powder can be decreased using a $\mathrm{H}_{2}$-containing gas. The low cost and abundance of $\mathrm{H}_{2}$ could facilitate the use of this technique in various industrial applications. [doi:10.2320/matertrans.MT-Y2021001]

(Received May 26, 2021; Accepted July 1, 2021; Published August 20, 2021)

Keywords: gas-atomized powder, synchrotron X-ray analysis, computed tomography, porosity, hydrogen

\section{Introduction}

There has been extensive research in recent years on consolidation technology for soft-magnetic non-equilibrium materials, such as amorphous and nanocrystal materials, and additive manufacturing technology. ${ }^{1-4)}$ Gas-atomized powder is often used as a raw material for these processes. Gas atomization involves spraying a high-pressure cooling medium, such as an inert gas or water, on a molten-metal stream that is pulverized into small droplets. This technique allows the preparation of powders with spherical particles and high flowability. Gas atomization with an inert gas facilitates the synthesis of high-quality powders with excellent flowability because of their clean surfaces. Therefore, it is used to produce powders that function as raw materials for the synthesis of various high-value-added products, such as amorphous, nanocrystal materials and raw powders for additive manufacturing. ${ }^{5-9}$ ) However, some particles in gas-atomized powders contain internal pores; furthermore, the volume of pores in these powders is higher than that in powders formed via other techniques, such as the plasma-rotating electrode process. ${ }^{10-12)}$ The presence of pores may result in the degradation of various properties of the final product.

Soft-magnetic amorphous and nanocrystal materials have attracted significant attention for use in energy-saving technologies. It is necessary to prevent the crystallization and coarsening of nanocrystals during consolidation. This can be achieved via the application of a high pressure in the low-temperature region $\left(400-500^{\circ} \mathrm{C}\right)$ for a short time

\footnotetext{
${ }^{* 1}$ This Paper was Originally Published in Japanese in J. Jpn. Soc. Powder Powder Metallurgy 68 (2021) 167-174.

${ }^{* 2}$ Corresponding author, E-mail: noriharu.yodoshi@gmail.com
}

(typically less than $3 \mathrm{~min}$ ), or "cold pressing". 13,14) The primary drawback of powder consolidation by low-temperature pressing is that some of the internal pores in the powder particles remain even after consolidation. This results in the deterioration of the soft-magnetic properties. ${ }^{15}$ In conventional high-temperature sintering, the gas contained in the pores formed between the powder particles during necking of the particles, along with that in the closed pores in the powder, can diffuse outside the sintered body. The total removal of all pores results in the complete densification of the sintered body. In contrast, non-equilibrium materials, such as amorphous powders, attain high relative densities under high applied pressures via consolidation as a result of softening in the relaxation region or the supercooled liquid region just before crystallization. ${ }^{16-18)}$ Although the pores in the powder are compressed under the applied pressure and decrease in size, the pores remain in a state of high internal pressure. Furthermore, a high residual stress is generated in the consolidated specimen. The densification mechanism for consolidation of the non-equilibrium phase is different from that for conventional crystalline materials. Therefore, the presence of pores in the powder particles of the raw non-equilibrium materials, which has not previously been a significant issue for other materials, exerts a detrimental effect on the characteristics of the products.

An electron beam is utilized for melting in powder-bed fusion additive manufacturing. ${ }^{19,20)}$ In this case, it is necessary to maintain the powder bed under vacuum. Therefore, the release of gas from the interior of the powder during fusion of the particles must be suppressed as much as possible. However, the expansion of the remaining pores inside the product during subsequent heat treatment can result in defects that degrade the mechanical properties of the final product. ${ }^{21)}$ 
The formation of pores in gas-atomized powders is a significant challenge that impedes the development and processing of novel materials. However, the formation mechanism of internal pores has not yet been elucidated in detail; in addition, a method to suppress the formation of pores has not been established to date. The quantitative analysis of the porosity, i.e., the pore size and volume, of fine powders is difficult because standard evaluation criteria have not been established. The purpose of the present study is to obtain computed tomography (CT) images of the interior of gas-atomized $\mathrm{Fe}_{76} \mathrm{Si}_{9} \mathrm{~B}_{10} \mathrm{P}_{5}$ powders using synchrotron $\mathrm{X}$-rays and develop a strategy for reducing the total pore volume in the powder.

The formation of pores in gas-atomized powders is attributed to several factors:

(1) Diffusion of the dissolved gas from the molten metal to the atmosphere during cooling.

(2) Cavitation induced by supersonic or subsonic atomization conditions.

(3) Formation of shrinkage cavities during solidification (excluding amorphous materials).

(4) Gas entrapment during the formation and recombination of droplets.

A combination of these factors induces the formation and growth of pores, which depends on the alloy, temperature of the molten metal, and atomization conditions. Recent reports have suggested that gas entrapment during the crushing and recombination of droplets is the primary cause of pore formation. ${ }^{22)}$

The use of a low-pressure gas during spraying prevents gas entrapment during crushing of the molten-metal stream and subsequent quenching during droplet flight. However, a decrease in the gas-spray pressure induces a decrease in the crushing force. This can result in larger powder particles, a higher proportion of irregularly shaped particles, and a decrease in the cooling rate. Therefore, it is necessary to investigate the effect of using low gas-spray pressure during atomization on the morphology and microstructure of the powder particles.

Generally, the existing bubbles in a liquid are discharged to the exterior to minimize the surface energy of the liquid. If sufficient time is available, then all types of gas bubbles inside the molten-metal droplets, including those originating from gas entrapment and gas discharge from the molten metal, will be removed. However, the presence of an oxide film on the surface of the particles and bubbles may hinder the diffusion and removal of the gas. This is particularly challenging as cooling and solidification occur rapidly after droplet formation. The completion of solidification prior to complete gas removal results in the formation of internal pores. Minimizing the formation of surface oxide layers allows the removal of most gas from the droplet, resulting in a lower total volume of internal pores.

$\mathrm{Fe}_{76} \mathrm{Si}_{9} \mathrm{~B}_{10} \mathrm{P}_{5}$ was selected in this study as a representative soft-magnetic amorphous material as it has a high amorphous-forming ability and excellent soft-magnetic properties. $^{23,24)} \mathrm{A}$ detailed analysis of the effect of the atomization conditions on the morphology, microstructure, and internal pore volume of the powder particles was performed. We experimentally verified the hypothesis that the presence of a reducing gas during atomization can suppress the oxidation of the droplet surface and enhance gas removal from the particles.

\section{Experimental Procedure}

$\mathrm{Fe}_{76} \mathrm{Si}_{9} \mathrm{~B}_{10} \mathrm{P}_{5}$ (atomic \%) was prepared using a highfrequency melting furnace (VMF-1-11, Diavac Ltd., Japan) under an Ar atmosphere. Approximately 50-70 g of the prepared ingot was melted again and pulverized via gas atomization (RQM-P-100, Makabe Giken Ltd., Sendai, Japan). Three different atomization gas mixtures were used: pure $\mathrm{Ar}$ (purity: $\geq 99.998 \%, \mathrm{O}_{2}$ concentration $\leq 5 \mathrm{ppm}$ ); pure Ar mixed with $3 \% \mathrm{H}_{2}$; and pure Ar mixed with $7 \% \mathrm{H}_{2}$. The gas pressure was set to $1.5 \mathrm{MPa}$ or $10 \mathrm{MPa}$ for pure Ar, and $10 \mathrm{MPa}$ for $\mathrm{Ar}-\mathrm{H}_{2}$ mixtures. These conditions are henceforth referred to as Ar@1.5 MPa, Ar@10 MPa, Ar+ $3 \% \mathrm{H}_{2} @ 10 \mathrm{MPa}$, and $\mathrm{Ar}+7 \% \mathrm{H}_{2} @ 10 \mathrm{MPa}$.

The size of the obtained powder particles was selected using a mesh filter $(\leq 125 \mu \mathrm{m})$. The surface morphology of the powder was observed using scanning electron microscopy (SEM; S-3400N, Hitachi High-Technologies Corporation, Tokyo, Japan) without any sample coating. The particle-size distribution and particle shape (circularity and aspect ratio), were analyzed via static image analysis (Morphologi 4, Malvern Panalytical Ltd., Malvern, UK). The circularity is defined as the ratio of the circumference of a circle with an area equal to that of the projected object to the circumference of the object. The aspect ratio is defined as the ratio of the minor-axis diameter to the major-axis diameter of the particles. The crystal structure of the powders was investigated via X-ray diffraction (XRD; Ultima-IV, Rigaku Corporation, Tokyo, Japan) using $\mathrm{Cu} K \alpha$ radiation (20-90 $2 \theta, 40 \mathrm{kV}, 40 \mathrm{~mA})$. Thermal analysis was performed via differential scanning calorimetry (DSC; EXSTAR6300, Seiko Instruments Inc., Chiba, Japan) at a heating rate of $0.67 \mathrm{~K} / \mathrm{s}$ under Ar atmosphere. Samples with a weight of $\sim 10 \mathrm{mg}$ were used.

The pores in the powder particles were evaluated using synchrotron X-ray CT (BL8S2 beamline, Aichi Synchrotron Radiation Center, Aichi, Japan). A 3D model was created by reconstructing the $\mathrm{CT}$ data, and image analysis was performed. The powder specimen was mixed with the resin and fixed to a cylindrical rod, with a diameter of $1 \mathrm{~mm}$, at a height of approximately $1 \mathrm{~mm}$. White X-rays $(6-24 \mathrm{keV})$ were transmitted through the specimen that was rotated over $360^{\circ}$, and 3601 images were captured in $0.1^{\circ}$ increments. The transmitted image was captured using an image sensor through a $10 \times$ objective lens. The image resolution and field size were $0.65 \times 0.65 \mu \mathrm{m}^{2} /$ pixel and $1.3 \times 1.3 \mathrm{~mm}^{2}$, respectively.

\section{Results and Discussions}

Figure 1 shows SEM images of the powders prepared under various atomization conditions. Most of the observed powder particles were spherical, consistent with gas atomization. $\mathrm{Fe}_{76} \mathrm{Si}_{9} \mathrm{~B}_{10} \mathrm{P}_{5}$ exhibits an amorphous-forming ability, and the surface of the spherical powder was smooth. Furthermore, neither a contrast, owing to the crystal structure, 
(a)

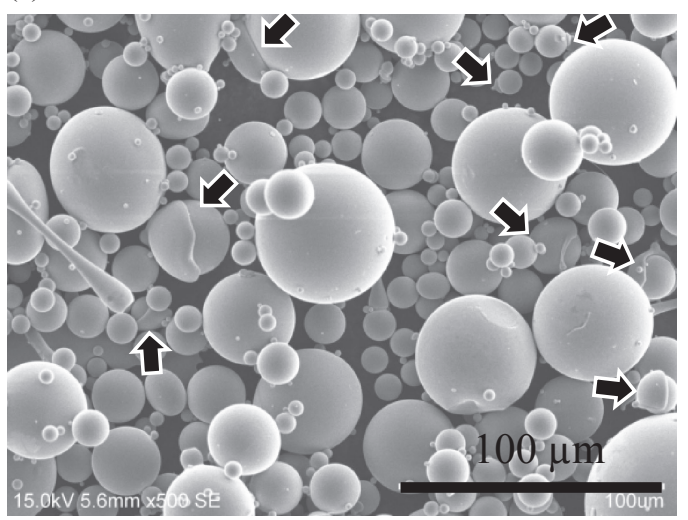

(b)

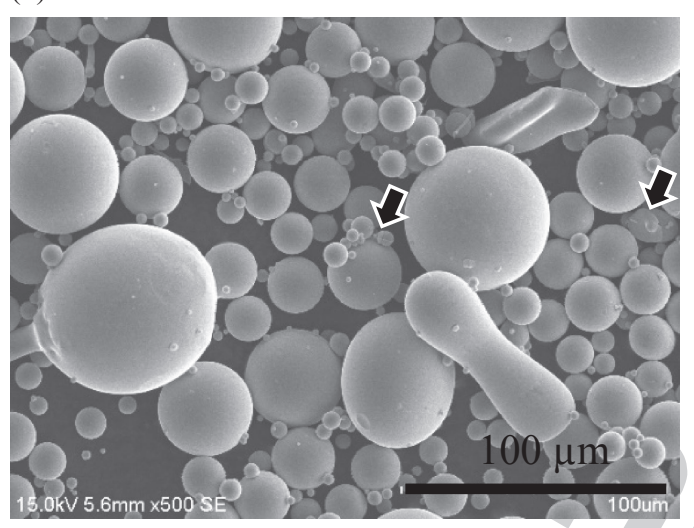

(c)

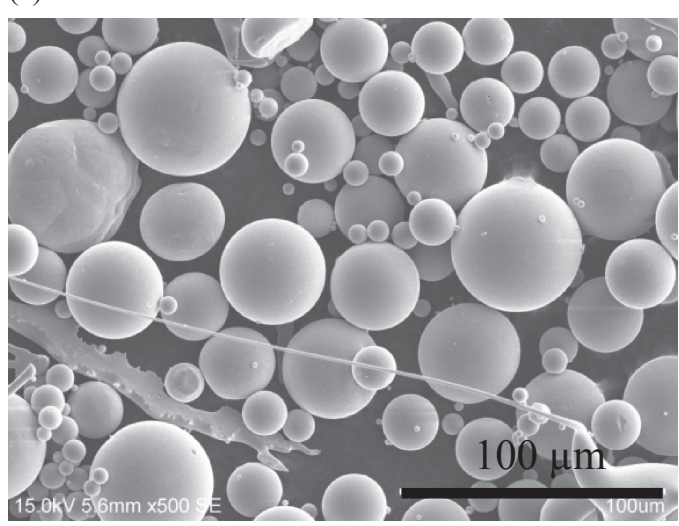

Fig. 1 SEM images of the $\mathrm{Fe}_{76} \mathrm{Si}_{9} \mathrm{~B}_{10} \mathrm{P}_{5}$ powders below $125 \mu \mathrm{m}$ prepared by gas-atomization under (a) $10 \mathrm{MPa} \mathrm{Ar}$, (b) $10 \mathrm{MPa} \mathrm{Ar}+3 \% \mathrm{H}_{2}$, (c) 1.5 MPa Ar. nor indentations, owing to shrinkage cavities, were detected. Elongated string-like particles were observed owing to solidification in a state of deep supercooling below the melting point. This indicated that the droplets were subjected to the crushing force of the gas, even at low temperatures. Some Ar@10 MPa particles had traces of other particles covering the surface, as indicated by the arrows in the SEM image (Fig. 1(a)). Fewer such traces were observed on the $\mathrm{Ar}+3 \% \mathrm{H}_{2} @ 10 \mathrm{MPa}$ powder (Fig. 1(b)) than the Ar@10 $\mathrm{MPa}$ powder (Fig. 1(a)). The traces of other particles covering the surface were negligible on the powder sprayed with Ar@1.5 MPa (Fig. 1(c)). This powder had long stringlike structures in which the finely drawn stream appeared to have undergone solidification without crushing.

Table 1 shows the relationship between the atomization conditions and the particle morphologies of the obtained powders. The volume-based median diameter $\left(D_{V 50}\right)$ values of the powder prepared using $\mathrm{Ar} @ 10 \mathrm{MPa}$ and $\mathrm{Ar}+$ $3 \% \mathrm{H}_{2} @ 10 \mathrm{MPa}$ were 55.7 and $47.3 \mu \mathrm{m}$, respectively. The powder prepared using Ar@1.5 MPa had a high $D_{V 50}$ of $84.0 \mu \mathrm{m}$, which was attributed to a lower crushing force of the gas on the molten-metal stream due to the lower gas pressure. The circularity and aspect ratio of this powder were 0.94 and 0.87 , respectively, while these values were as high as 0.97 for particles produced at a higher gas pressure of $10 \mathrm{MPa}$. Here, particles with a circularity of $\geq 0.85$ and an aspect ratio of $\geq 0.88$ are considered spherical. The fraction of spherical particles in the powders prepared using a gas pressure of 10 and $1.5 \mathrm{MPa}$ was approximately $90 \%$ and $\leq 50 \%$, respectively. These results indicated that the use of a low-pressure gas for spraying induced an increase in the size of the powder particles and consequently, a higher proportion of irregular string-like particles were observed (Fig. 1(c)).

Figure 2(a) presents the XRD patterns of the powders prepared under the various atomization conditions. The XRD patterns of the two powders prepared using a pressure of $10 \mathrm{MPa}$ (Ar@10 MPa and $\mathrm{Ar}+3 \% \mathrm{H}_{2} @ 10 \mathrm{MPa}$ ) had only a broad pattern corresponding to the amorphous phase. However, the XRD pattern of the Ar@1.5 MPa powder also had an additional diffraction peak corresponding to the crystalline $\alpha$-Fe phase. When the cooling rate is lower than the critical cooling rate for the formation of an amorphous phase in $\mathrm{Fe}_{76} \mathrm{Si}_{9} \mathrm{~B}_{10} \mathrm{P}_{5}$, the $\alpha$-Fe phase is precipitated. ${ }^{25)}$ Hence, the lower gas pressure did not provide a sufficiently high cooling rate for the formation of the amorphous phase.

Figure 2(b) presents the DSC curves of the Ar@1.5 MPa, $\mathrm{Ar} @ 10 \mathrm{MPa}$, and $\mathrm{Ar}+3 \% \mathrm{H}_{2} @ 10$ powders, which are compared to a ribbon specimen prepared via single-roll melt

Table 1 Characteristics of morphology (Median diameter $D_{V 50}$, Circularity, Aspect ratio, Fraction of spherical particle) of various powders.

\begin{tabular}{|l|c|c|c|c|}
\hline \multicolumn{1}{|c|}{ Gas condition } & $\begin{array}{c}D v_{50} \\
{[\mu \mathrm{m}]}\end{array}$ & Circularity & Aspect ratio & $\begin{array}{c}\text { Fraction of spherical particle* } \\
{[\%]}\end{array}$ \\
\hline $10 \mathrm{MPa} \mathrm{Ar}$ & 55.7 & 0.97 & 0.97 & 89.6 \\
\hline $10 \mathrm{MPa} 3 \% \mathrm{H}_{2}+\mathrm{Ar}$ & 47.3 & 0.97 & 0.97 & 88.0 \\
\hline $1.5 \mathrm{MPa} \mathrm{Ar}$ & 84.0 & 0.94 & 0.87 & 48.9 \\
\hline
\end{tabular}

※ Aspect Ratio $\geqq 0.88$ and HS Circularity $\geqq 0.85$ 
(a)

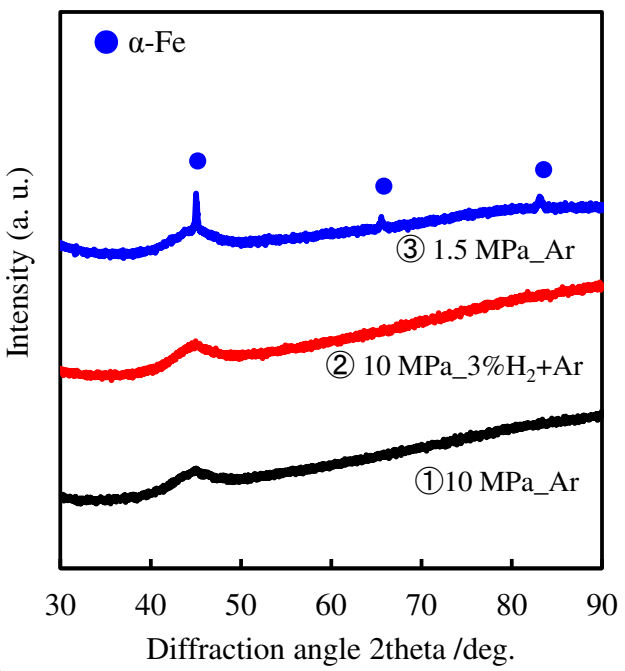

(b)

Heating rate: $0.67 \mathrm{~K} / \mathrm{s}$

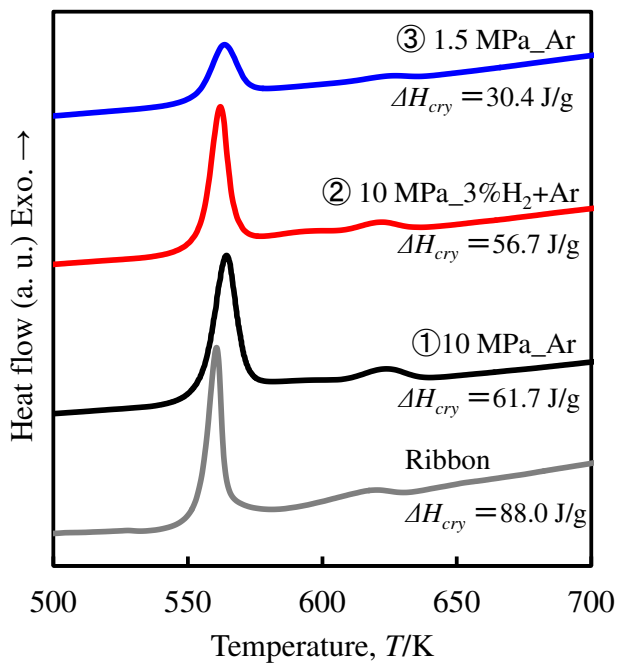

Fig. 2 (a) XRD patterns, (b) DSC curves of various powders.

spinning. The DSC curves for all specimens had an exothermic peak corresponding to the crystallization of the amorphous phase at $\sim 550^{\circ} \mathrm{C}$. However, the ribbon specimen had the highest calorific value of crystallization $(88.0 \mathrm{~J} / \mathrm{g})$, where the values for the $\mathrm{Ar}+3 \% \mathrm{H}_{2} @ 10 \mathrm{MPa}$ and $\mathrm{Ar} @ 10$ $\mathrm{MPa}$ powders were 56.7 and $61.7 \mathrm{~J} / \mathrm{g}$, respectively. These results were attributed to the differences in the cooling rate during the formation of the amorphous phase. When the atomization pressure was $1.5 \mathrm{MPa}$, the calorific value of crystallization decreased to $30.4 \mathrm{~J} / \mathrm{g}$. This was attributed to the different microstructure formed with the lower cooling rate, even though the particle-size range was similar for all powder specimens.

Figure 3(a) shows a representative image captured via the transmission of synchrotron X-rays through a resin-mounted powder specimen. Figure 3(b) shows a 3D reconstructed model obtained via CT processing of all captured images. Most of the pores in the powder particles were confirmed to be spherical. The reconstructed image could be rotated in all dimensions to take arbitrary cross-sections, such as that shown in Fig. 3(c). If the particles contained pores, then the shape and dimensions of the pores were identified. Figure 3(d) shows a representative cross-sectional particle from the model containing a central pore. The number of particles containing pores, particle volume (corresponding to the voxels), particle size (corresponding to the sphereequivalent diameter calculated from the voxels), number of internal pores, pore volume, and pore size were obtained from the $3 \mathrm{D}$ visualization. The resolution of the synchrotron X-ray CT image was $0.65 \mu^{2} /$ pixel. To prevent the recognition of noise as particles (or pores) during image analysis, the particles and pores with sphere-equivalent diameters less than $6.5 \mu \mathrm{m}$ were excluded from the analysis. The cumulative data were collected for at least 5000 particles of each sample type. The number of target particles used for powders prepared at 10 and $1.5 \mathrm{MPa}$ was $\geq 10000$ and 7690 , respectively.

Table 2 presents the number and volume statistics of the particles and pores for powders prepared using the various atomization conditions. A total of 12551 particles with diameters of $\geq 6.5 \mu \mathrm{m}$ were analyzed for the Ar@10 MPa powder. The total volume of the particles was $7.59 \times$ $10^{-11} \mathrm{~m}^{3}$. These particles contained 68 pores with sphereequivalent diameters of $\geq 6.5 \mu \mathrm{m}$, and the total volume of the pores was $1.01 \times 10^{-13} \mathrm{~m}^{3}$. Therefore, this sample contained $8.96 \times 10^{11}$ pores $/ \mathrm{m}^{3}$. The volume ratio and number ratio of the pores in the powder were $1.33 \times 10^{-3}$ and $5.42 \times 10^{-3}$, respectively. The number ratio of the pores indicates the probability of the presence of pores in each particle. Thus, synchrotron radiation $\mathrm{X}$-ray $\mathrm{CT}$ is an effective method for determining the number and volume of pores in such powder samples.

Figure 4(a) presents the porosity volume ratio in the powders prepared under various atomization conditions. There was a significant decrease in the total volume of pores in the powders with decreasing atomization pressure. This was attributed to the low probability of particle recombination and associated gas entrapment after crushing due to the low pressure. The porosity volume ratio was lower for the powder prepared using $\mathrm{Ar}-\mathrm{H}_{2}$ mixtures than that for the powder prepared using pure Ar. The porosity volume ratio of the Ar@1.5 MPa and $\mathrm{Ar}+7 \% \mathrm{H}_{2} @ 10 \mathrm{MPa}$ samples were approximately half of that of Ar@10 MPa.

Figure 4(b) shows the pore number ratio (number of internal pores divided by the total number of particles). For the powders produced with an atomization pressure of $10 \mathrm{MPa}$, the variations in the volume ratio and number ratio were similar. However, for an atomization pressure of 1.5 $\mathrm{MPa}$, the lowest volume ratio and highest number ratio of pores were observed. This corresponded to a high probability of the presence of pores in each particle because the average particle size was high.

Figure 5 presents a distribution map of pore diameter versus particle diameter data obtained from the CT analysis, for only the powder particles containing pores. The points plotted in the gray region of the figure represent the particles containing pores with diameters of $\geq 20 \mu \mathrm{m}$. The Ar@10 MPa powder had the most points in this region, followed by 
(a)

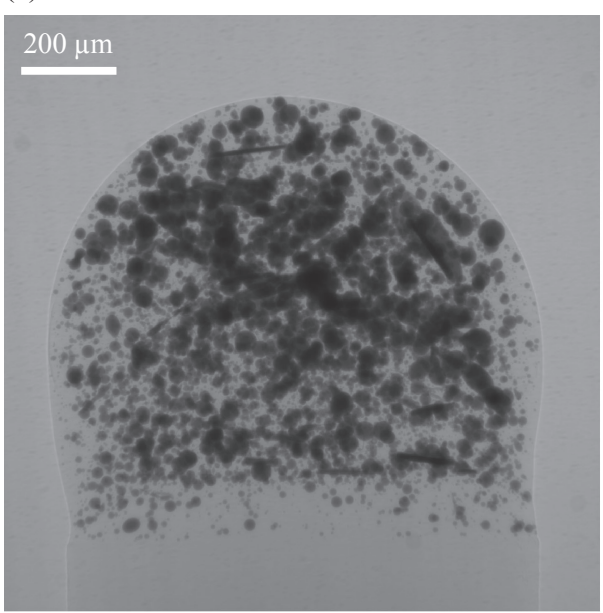

(c)

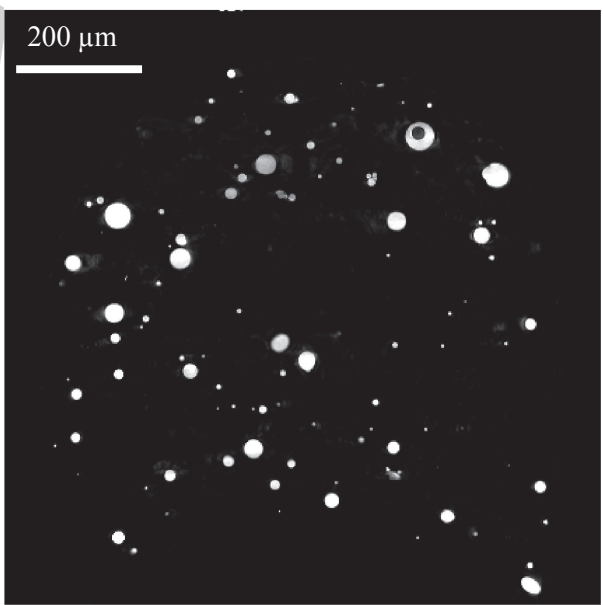

(b)

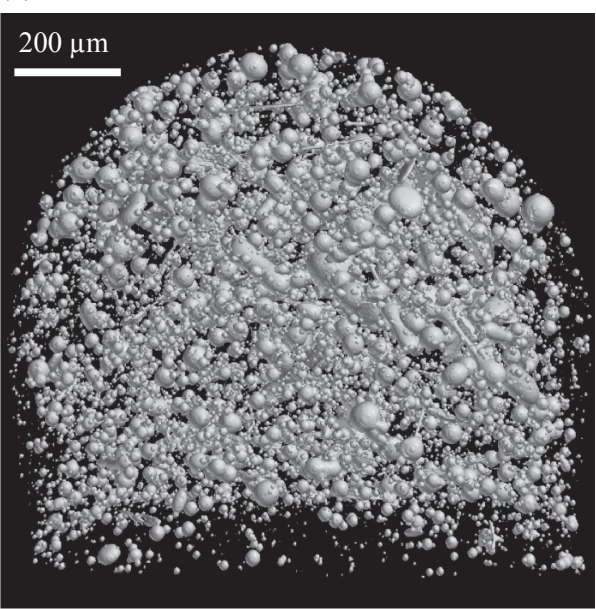

(d)

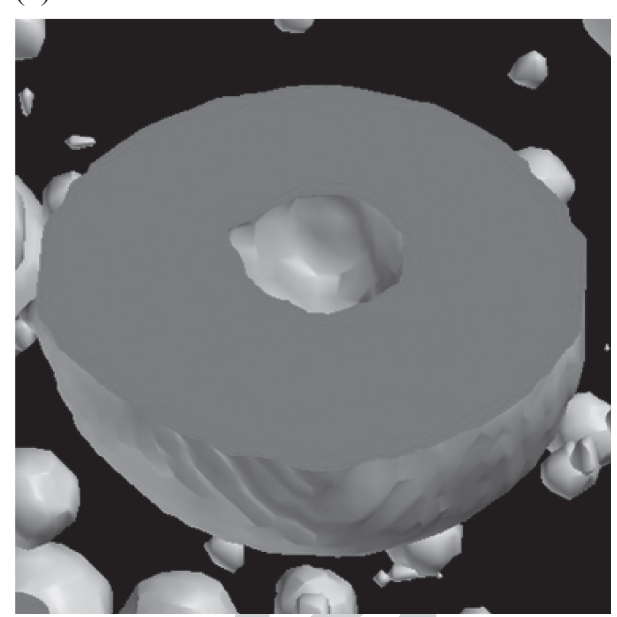

Fig. 3 Morphological image of atomized powders analyzed by synchrotron X-ray CT scan. (a) Transmitted X-ray image, (b) 3D image after reconstruction, (c) Cross-sectional image, (d) 3D visualization of the incorporated porosity.

Table 2 Statistical data from quantification of the porosity in various powders

(over 6.5 micron)

\begin{tabular}{|c|c|c|c|c|c|c|c|}
\hline \multirow{2}{*}{ Condition } & \multicolumn{2}{|c|}{ Powder Particle } & \multicolumn{2}{c|}{ Pore } & \multicolumn{3}{c|}{ Porosity } \\
\cline { 2 - 8 } & Number & Volume & Number & Volume & $\begin{array}{c}\text { Number per } \\
\text { unit volume }\end{array}$ & $\begin{array}{c}\text { Volume } \\
\text { ratio }\end{array}$ & $\begin{array}{c}\text { Number } \\
\text { ratio }\end{array}$ \\
\cline { 2 - 8 } & - & $\mathrm{m}^{3}$ & - & $\mathrm{m}^{3}$ & $\mathrm{~m}^{-3}$ & - & - \\
\hline $\mathrm{Ar}$ & 12551 & $7.59 \mathrm{E}-11$ & 68 & $1.01 \mathrm{E}-13$ & $8.96 \mathrm{E}+11$ & $1.33 \mathrm{E}-03$ & $5.42 \mathrm{E}-03$ \\
\hline $3 \% \mathrm{H}_{2}$ & 13869 & $7.83 \mathrm{E}-11$ & 57 & $8.09 \mathrm{E}-14$ & $7.28 \mathrm{E}+11$ & $1.03 \mathrm{E}-03$ & $4.11 \mathrm{E}-03$ \\
\hline $7 \% \mathrm{H}_{2}$ & 11854 & $4.88 \mathrm{E}-11$ & 30 & $3.26 \mathrm{E}-14$ & $6.15 \mathrm{E}+11$ & $6.67 \mathrm{E}-04$ & $2.53 \mathrm{E}-03$ \\
\hline Low_P Ar & 7690 & $8.79 \mathrm{E}-11$ & 65 & $5.51 \mathrm{E}-14$ & $7.39 \mathrm{E}+11$ & $6.27 \mathrm{E}-04$ & $8.45 \mathrm{E}-03$ \\
\hline
\end{tabular}

$\mathrm{Ar}+3 \% \mathrm{H}_{2} @ 10 \mathrm{MPa}$, while Ar+7\% $\mathrm{H}_{2} @ 10 \mathrm{MPa}$ and Ar@1.5 $\mathrm{MPa}$ only showed one instance of such a large pore. Hence, both the presence of the reducing gas during atomization, and the use of the lower atomization pressure significantly decreased the number of large pores. In the case of the low pressure, the low crushing force of the gas on the moltenmetal stream or droplets reduced the likelihood of gas entrapment. Figure 4(a) and Fig. 5 revealed that the specimen with a high volume ratio of pores contained numerous large pores; furthermore, a decrease in the number of large pores resulted in a decrease in the volume fraction of pores.
Figure 6 shows the mechanism via which gas entrapment induces the formation of pores inside a powder. Gas atomization involves the coarse pulverization of a moltenmetal stream under a high-pressure gas spray and the subsequent stripping breakup of large droplets into relatively small droplets. ${ }^{26,27)}$ Some of the small droplets collide with the large droplets and coalesce into larger ones. This may result in the entrapment of the gas. The trapped gas forms a spherical bubble that is discharged to the exterior of the droplet. The droplet surface is readily oxidized due to the presence of $\mathrm{O}_{2}$ in the atomization gas, resulting in a hard and 
(a)

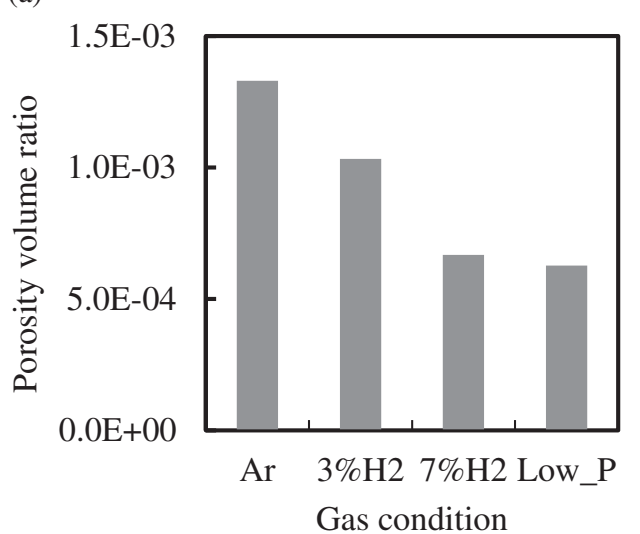

(b)

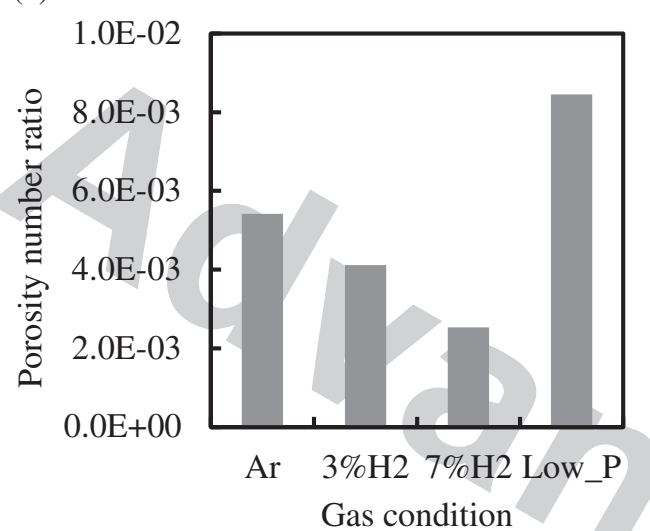

Fig. 4 Quantification data of the porosity in various powders. (a) Porosity volume ratio (fraction), (b) Porosity number ratio.

slaggy (highly viscous) oxide film. The oxide film is present during the collision and coalescence process and inhibits the formation of spherical particles during the coalescence of droplets and removal of trapped gas. When the atomization gas contains a reducing gas, such as $\mathrm{H}_{2}$, the formation of surface oxides is minimized, and the droplet surface remains relatively clean during cooling. This allows complete coalescence of the droplets and removal of gas bubbles, owing to the surface tension, to occur before the particle is fully solidified. Gas atomization involves rapid cooling in an extremely short time. Therefore, the slight difference in deformation resistance provided by the surface oxidation has

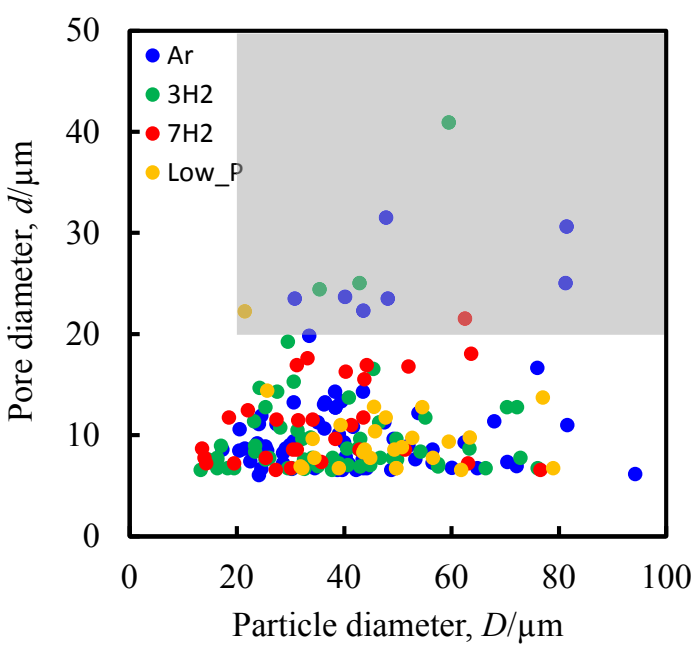

Fig. 5 Plot of pore equivalent diameter versus diameter of the powder particle containing pore.

a significant influence on the final quantity of pores in the powder particles.

This study demonstrated that the use of a reducing atomizing gas effectively decreased the number of pores in gas-atomized $\mathrm{Fe}_{76} \mathrm{Si}_{9} \mathrm{~B}_{10} \mathrm{P}_{5}$ powder. The demonstrated method requires various safety measures; however, it can be applied, without any major modifications, to the conventional gas-atomization equipment. Furthermore, the abundance and low cost of $\mathrm{H}_{2}$ makes it viable for use in gas atomization processes. The presence of $\mathrm{H}_{2}$ in the gas spray allows the synthesis of high-quality powders, even with a low-purity inert gas, which is highly beneficial for industrial applications.

\section{Conclusion}

This study demonstrated the preparation of soft-magnetic and amorphous $\mathrm{Fe}_{76} \mathrm{Si}_{9} \mathrm{~B}_{10} \mathrm{P}_{5}$ via gas atomization with different gas mixtures and pressures. The morphology of the powder particles was investigated using static image analysis, and the number of pores in the prepared powders was quantitatively analyzed using synchrotron X-ray CT.

(1) The use of a low gas pressure induced an increase in the average size of the powder particles. Consequently, a

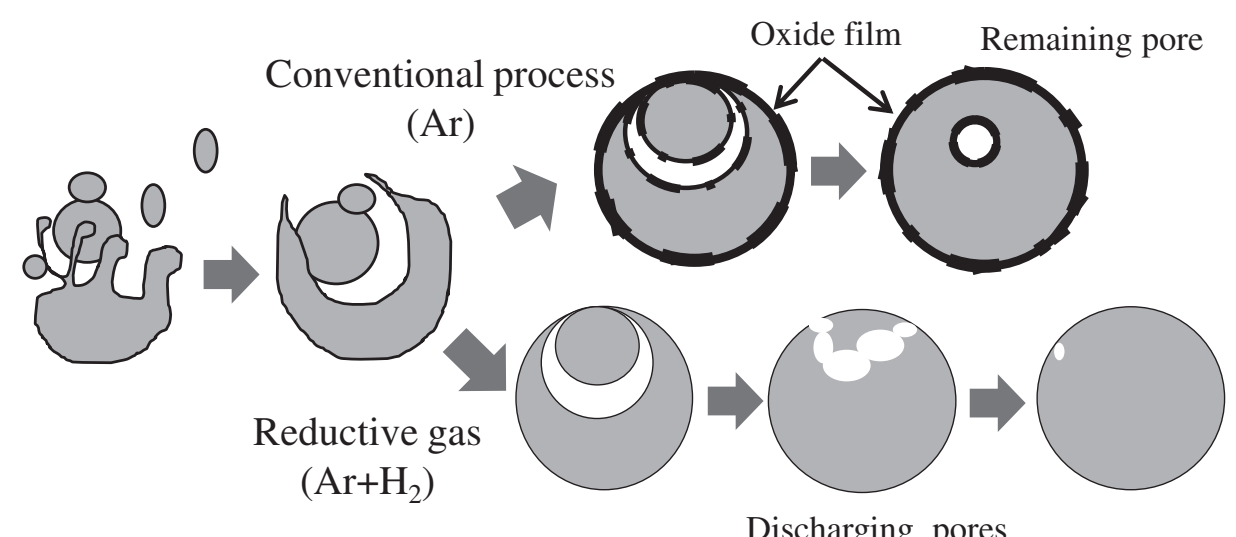

Fig. 6 Schematic illustration of the pore formation/elimination mechanism in the atomized powders. 
high fraction of irregular-shaped powder particles was detected. In addition, a decrease in the cooling rate resulted in the partial precipitation of the crystalline $\alpha$-Fe phase.

(2) The use of $\mathrm{Ar}-\mathrm{H}_{2}$ gas mixtures resulted in fewer pores in the powder particles compared to the use of pure $\operatorname{Ar}$ (e.g., approximately half the total number of pores using $7 \% \mathrm{H}_{2}$ ). A corresponding decrease in the total pore volume was observed due to a significant decrease in the number of large pores.

(3) When the molten-metal stream was atomized under high-pressure $\mathrm{Ar}-\mathrm{H}_{2}$ gas, the surface oxidation of the droplet was suppressed, which enhanced the removal of trapped gas bubbles before solidification.

As further work, it is necessary to investigate the extent to which the total number of pores in the powder can be decreased by increasing the concentration of $\mathrm{H}_{2}$ in the atomization gas. Furthermore, it is crucial to experimentally clarify whether the demonstrated method can be applied to other alloy systems, such as those that form a compound phase with $\mathrm{H}_{2}$ and those that contain elements with high oxygen affinity. It is also critical to apply a combination of simulations and experiments to investigate the effect of the nozzle angle and chamber shape on the crushing and recollision of the droplets during atomization.

\section{Acknowledgments}

The present research was performed with the support of KAKENHI (grant number 18K04767). The synchrotron radiation X-ray $\mathrm{CT}$ observations were performed at the BL8S2 beamline of the Aichi Synchrotron Radiation Center (Proposal No. 2020P0104). The authors appreciate the technical support provided by Dr. Ikuya Sakurai of Nagoya University, and Dr. Kenji Hanada and Mr. Tetsuo Nagami of the Aichi Science \& Technology Foundation. Dr. Yasuyuki Fukuda of Makabe Giken Co., Ltd. and Dr. Keisuke Ito of the Industrial Technology Institute Miyagi are acknowledged for their fruitful discussions.

\section{REFERENCES}

1) N. Ciftci, N. Yodoshi, S. Armstrong, L. Madler and V. Uhlenwinkel: J. Mater. Sci. Technol. 59 (2020) 26-36.

2) J. Luan, P. Sharma, N. Yodoshi, Y. Zhang and A. Makino: AIP Adv. 6 (2016) 055934
3) H.Y. Jung, S.J. Choi, K.G. Prashanth, M. Stoica, S. Scudino, S. Yi, U. Kuhn, D.H. Kim, K.B. Kim and J. Eckert: Mater. Des. 86 (2015) 703-708.

4) X.D. Nong, X.L. Zhou and Y.X. Ren: Opt. Laser Technol. 109 (2019) 20-26.

5) N. Ciftci, N. Ellendt, E.S. Barreto, L. Madler and V. Uhlenwinkel: Adv. Powder Technol. 29 (2018) 380-385.

6) J. Boes, A. Röttger, W. Theisen, C. Cui, V. Uhlenwinkel, A. Schulz, H.-W. Zoch, F. Stern, J. Tenkamp and F. Walther: Addit. Manuf. 34 (2020) 101379.

7) D. Riabov, E. Hryha, M. Rashidi, S. Bengtsson and L. Nyborg: Surf. Interface Anal. 52 (2020) 694-706.

8) A. Martín, C.M. Cepeda-Jiménez and M.T. Pérez-Prado: Adv. Eng. Mater. 22 (2020) 1900594.

9) T. Fedina, J. Sundqvist, J. Powell and A.F.H. Kaplan: Addit. Manuf. 36 (2020) 101675.

10) S. Tammas-Williams, H. Zhao, F. Leonard, F. Derguti, I. Todd and P.B. Prangnell: Mater. Charact. 102 (2015) 47-61.

11) G. Chen, Q. Zhou, S.Y. Zhao, J.O. Yin, P. Tan, Z.F. Li, Y. Ge, J. Wang and H.P. Tang: Powder Technol. 330 (2018) 425-430.

12) G. Chen, S.Y. Zhao, P. Tan, J. Wang, C.S. Xiang and H.P. Tang: Powder Technol. 333 (2018) 38-46.

13) K.L. Alvarez, H.A. Baghbaderani, J.M. Martin, N. Burgos, M. Ipatov, Z. Pavlovic, P. McCloskey, A. Masood and J. Gonzalez: J. Magn. Magn. Mater. 501 (2020) 166457.

14) J.H. Wang, Z.L. Guo, Q.T. Zeng, G.H. Hang, Z.L. Xue, D.C. Chen, Z.K. Liang and H.B. Sun: J. Magn. Magn. Mater. 510 (2020) 166931.

15) Japanese Patent No. 6448799

16) N. Yodoshi, R. Yamada, A. Kawasaki and R. Watanabe: Mater. Trans. 50 (2009) 2264-2269.

17) R. Watanabe, N. Yodoshi, H. Kato and A. Kawasaki: J. Jpn. Soc. Powder Metall. 55 (2008) 709-714.

18) X.X. Li, C. Yang, T. Chen, L.C. Zhang, M.D. Hayat and P. Cao: J. Alloys Compd. 802 (2019) 600-608.

19) L.E. Murr, S.M. Gaytan, A. Ceylan, E. Martinez, J.L. Martinez, D.H. Hernandez, B.I. Machado, D.A. Ramirez, F. Medina, S. Collins and R.B. Wicker: Acta Mater. 58 (2010) 1887-1894.

20) D.A. Ramirez, L.E. Murr, E. Martinez, D.H. Hernandez, J.L. Martinez, B.I. Machado, F. Medina, P. Frigola and R.B. Wicker: Acta Mater. 59 (2011) 4088-4099.

21) S. Tammas-Williams, R.I. Withers, I. Todd and P.B. Prangnell: Scr. Mater. 122 (2016) 72-76.

22) S. Tammas-Williams, R.I. Withers, I. Todd and P.B. Prangnell: Metall. Mater. Trans. A 47 (2016) 1939-1946.

23) N. Yodoshi, R. Yamada, A. Kawasaki and A. Makino: J. Alloys Compd. 643 (2015) S2-S7.

24) A. Makino, T. Kubota, M. Makabe, C.T. Chang and A. Inoue: Mater. Sci. Eng. B 148 (2008) 166-170.

25) N. Yodoshi, S. Ookawa, R. Yamada, N. Nomura, K. Kikuchi and A. Kawasaki: Mater. Res. Lett. 6 (2018) 100-105.

26) ASM Handbook, vol. 7: Powder Metal Technologies and Applications, (ASM International, Almere, 1998) p. 152.

27) A.J. Yule and J.J. Dunkley: Atomization of Melts, (Oxford University Press, USA, 1994) pp. 40. 